\title{
O uso da associação azitromicina e N-metil glucamina no tratamento da leishmaniose cutânea causada por Leishmania (Leishmania) amazonensis em camundongos C57BL6*
}

\author{
The use of azythromycin and $\mathrm{N}$-methyl glucamine for the treatment \\ of cutaneous Leishmaniasis caused by Leishmania (Leishmania) amazonensis \\ in C57BL6 mice
}

Raimunda Nonata Ribeiro Sampaio ${ }^{1}$
Arnoldo Velloso da Costa Filho ${ }^{3}$

Resumo: FundAmENTOS: O tratamento de primeira escolha da leishmaniose tegumentar americana é a Nmetil-glucamina que tem alta toxicidade, exige administração parenteral e nem sempre cura. A azitromicina mostrou ação in vitro e resultado contraditório na doença humana.

Oвјетіvo: Verificar se a associação N-metil glucamina+azitromicina é mais eficaz do que N-metil glucamina no tratamento da leishmaniose experimental.

MÉTodos: 25 camundongos inoculados com a cepa C57BL/6 de $L$. (L.) amazonensis foram divididos em dois grupos. Um foi tratado com $400 \mathrm{mgSbV} / \mathrm{kg} / \mathrm{dia}$ de N-metil-glucamina associado a $200 \mathrm{mg} / \mathrm{kg} / \mathrm{dia}$ de azitromicina durante 20 dias, e o outro com N-metil glucamina, na mesma dose, durante o mesmo tempo. Foi feita avaliação clínica e parasitológica com análise estatística.

RESULTADO: Na avaliação clínica, pesquisa de amastigotas e das culturas, não houve diferença estatística. Verificou-se, entretanto, diferença significante no resultado das culturas realizadas através de diluição limitante, que desfavoreceu a associação NMG + azitromicina.

CONCLUSÃo: A associação N-metil glucamina e azitromicina não demonstrou mais eficácia do que o N-metil glucamina em uso isolado.

Palavras-chave: Azitromicina; Leishmaniose cutânea; Leishmaniose cutânea/terapia

* Trabalho realizado no Laboratório de Dermatomicologia da Universidade de Brasília (UnB) - Brasília (DF), Brasil.

Conflito de interesse: Nenhum / Conflict of interest: None

Suporte financeiro: Suporte Financeiro: Apoio financeiro parcial da Fundação de Empreendimentos Científicos e Tecnológicos - Finatec.

Professora-associada da Universidade de Brasília (UnB), Chefe do Serviço de Dermatologia do Hospital Universitário de Brasília (UnB) - Brasília (DF), Brasil . Aluna de Iniciação Científica da UnB-CNPq no período 2005/2006. Laboratório de Dermatomicologia da Universidade de Brasília (UnB) - Brasília (DF), Brasil. Aluno de Iniciação Científica da UnB-CNPq no período 2005/2006. Laboratório de Dermatomicologia da Universidade de Brasília (UnB) - Brasília (DF), Brasil. 


\section{INTRODUÇÃO}

A importância epidemiológica das leishmanioses na saúde pública demanda o desenvolvimento e o barateamento de medicamentos para tratá-las. Diversos fatores dificultam o controle dessas doenças: falta de vacina, grande variedade de espécies de leishmânias e flebótomos, falta de conhecimento e prevenção da doença pela população, entre outros.

O medicamento de primeira escolha para o tratamento das leishmanioses no Brasil e em outros países de língua não inglesa, é o antimonial pentavalente $\mathrm{N}$-metil-glucamina (NMG), droga de elevada toxicidade ${ }^{1-3}$ que requer administração parenteral e pode não ser efetiva no tratamento. ${ }^{2,4}$ Nesse caso, outras drogas, como anfotericina $\mathrm{B}$ clássica e pentamidina, que são também nefro-cardio-hepato-pancreatotóxicas e injetáveis, são utilizadas.

A azitromicina é antibiótico macrolídeo usado há mais de 40 anos em várias condições infecciosas, principalmente nas do trato respiratório e nas doenças sexualmente transmissíveis e com potencial atividade leishmanicida.$^{5.7}$ A classe dos macrolídeos atua inibindo a síntese proteica, dissociando o peptídio do ribossomo. ${ }^{6}$ Tem características como a de concentrarse nos tecidos, especialmente nos macrófagos, com níveis 100 a 200 vezes superiores do que no soro, tornando-a atrativa para o tratamento de infecções causadas por micro-organismos intracelulares. Outras vantagens são a possibilidade de administração por via oral ou injetável, boa biodisponibilidade oral e longa meia-vida, relativa segurança para uso em grávidas e crianças, e perfil de baixa toxicidade. Vários protozoários diferentes, como Plamodium falciparum, Plasmodium vivax e Toxoplasma gondii têm sido susceptíveis à azitromicina em experimentos in vitro e in vivo em diversos níveis. ${ }^{6}$

A azitromicina teve ação contra a $L$. major in vitro e in vivo, sem que, contudo, se conhecesse seu mecanismo de ação. Usando-a no tratamento de pacientes, foi demonstrada ação leishmaniostática com resposta terapêutica mais lenta do que a dos antimoniais. ${ }^{5}$ Em experimentações in vitro, a azitromicina não contribuiu para a fagocitose da $L$. major, mas aumentou a taxa de morte intracelular das amastigotas. ${ }^{8}$ Outra possibilidade é que a azitromicina tenha efeito imunomodulador, diminuindo-lhes o número e ativando neutrófilos e prevenindo a produção de mediadores e citocinas pró-inflamatórias. ${ }^{5,9}$ In vitro, também mostrou eficácia para $L$. (L.) amazonensis, $L$. (V.) brazililensis) e $L$. (L.) chagasi na concentração de $150 \mu \mathrm{g} / \mathrm{ml}^{10}$

Em estudo clínico realizado em Manaus, onde a espécie $L$. (V.) guyanensis é predominante, foi verificada baixa eficácia em 26 pacientes com leishmaniose cutânea (LC) que receberam essa droga por 20 dias sendo também observados efeitos colaterais como diarreia em $60 \%$, dor abdominal em $28 \%$, cefaleia e náuseas em $12 \% .{ }^{11}$ Outro estudo clínico avaliou a eficácia da azitromicina em três pacientes idosos com leishmaniose mucosa (LM) associada à cardiopatia crônica. A droga foi usada por via oral, em dose única diária de 500mg durante 10 dias, em três séries com intervalo de um mês. Foi observada boa resposta sem efeitos colaterais. Entretanto, dois pacientes tiveram recidiva após seis meses e foram curados com novo ciclo de azitromicina. ${ }^{12}$

O objetivo deste trabalho foi avaliar se a associação NMG+azitromicina é mais eficaz do que o tratamento de primeira escolha, NMG, da LC experimental causada por L.(L.) amazonensis.

\section{MATERIAIS E MÉTODOS}

Foram usados 25 camundongos isogênicos, machos, cepa $\mathrm{C} 57 \mathrm{BL} / 6$ procedentes do Instituto de Química do Estado de Goiás - Iquego. Os parasitos inoculados eram $L$. (L.) amazonensis obtidos de culturas da cepa PH8 mantidas criopreservadas no Laboratório de Dermatomicologia da UnB.

Antes do tratamento, foram realizadas medições dos diâmetros das patas dos animais. Estas foram inoculadas no coxim plantar direito com $3.10^{6}$ promastigotas metacíclicas de L.(L.) amazonensis e examinadas periodicamente para registrar o aparecimento das lesões cutâneas. Depois, os animais foram divididos de forma aleatória em dois grupos, um tratado com NMG dose de $400 \mathrm{mgSbV} / \mathrm{kg} / \mathrm{dia}$ IM durante 20 dias (grupo controle), e o outro com NMG na mesma dose associado a azitromicina $200 \mathrm{mg} / \mathrm{kg} /$ dia oral (através de gavagem), durante 20 dias.

Para medir as patas dos camundongos, foi usado paquímetro de precisão de décimos de milímetro.

Após o tratamento, os animais foram avaliados através de critérios clínico e parasitológico. Pelo critério clínico foram feitas medições das patas inoculadas, imediatamente antes e $\mathbf{2 0}$ dias após o tratamento.

A avaliação parasitológica foi feita pelo achado ou contagem de leishmânias em esfregaços, culturas em McNeal, Novy e Nicolle (NNN) e por cultura pelo método de diluição limitante.

Para realizar o esfregaço foi aspirado exsudato da pata inoculada dos camundongos. O mesmo foi colocado em lâmina, fixado, corado pelo Giemsa, sendo a leitura realizada em microscópio óptico.

Para realizar a cultura tradicional, o material aspirado foi colocado em tubo de cultura com meio $\mathrm{NNN}$, mantido em estufa a $24^{\circ} \mathrm{C}$, e a leitura realizada através de microscópio de luz invertida, diariamente, até completar um mês.

Para realizar a diluição limitante usou-se uma 
pata de cada grupo de camundongos. Em capela de fluxo laminar as mesmas foram dissecadas e trituradas e o conteúdo foi submetido a sucessivas diluições de 10 vezes e semeado em placas Elisa de 96 poços contendo meio RPMI enriquecido com soro bovino fetal. Foi usada uma placa para cada grupo, e elas foram mantidas em estufa $\mathrm{BOD}$ à temperatura de $24^{\circ} \mathrm{C}$ durante 30 dias. Os dados numéricos foram obtidos a partir da contagem do número de poços nos quais houve crescimento de promastigotas de leishmânia, verificado pela leitura em microscópio de luz invertida, e foi calculada a média dos valores obtidos para os dois grupos pelo programa Elida ${ }^{\circledR} .{ }^{13}$

Foram usados, também, os testes estatísticos t de Student e Qui-quadrado.

\section{RESULTADOS}

Antes do tratamento, compararam-se as medidas das patas dos camundongos nos dois grupos para evitar o viés de que já houvesse diferença antes do experimento (p: 0,11).

A média dos diâmetros das patas dos camundongos do grupo NMG+azitromicina foi maior do que a do grupo NMG (36,0 X 31,75mm), após o tratamento. Não houve também, diferença estatística significativa (p: 0,23), teste $\mathrm{t}$ de Student (Tabela 1).

$\mathrm{Na}$ avaliação parasitológica das culturas tradicionais realizadas após o tratamento, uma cultura foi positiva, e três negativas no grupo NMG+azitromicina, e duas positivas, e duas negativas no grupo NMG isolado. Não houve diferença estatística entre os dois grupos (teste de Fisher, calculado pelo módulo Statcalc do programa Epi Info 6.04 (p: 0,23).
De maneira semelhante foi calculada a diferença entre os dois grupos quanto à pesquisa de amastigotas nos esfregaços, cujos resultados foram dois esfregaços positivos e dois negativos no grupo NMG, e dois positivos e três negativos no grupo associação NMG + azitromicina $(p=0,23)$, teste de Fisher pelo mesmo programa anterior.

A estimativa do número médio de leishmânias presentes na pata de cada grupo de camundongo, através das culturas em diluição limitante, mostrou diferença entre os grupos (NMG: 528 leishmânias e associação NMG+AZITR: 12.700 leishmânias) (Tabela 2) (p: 0,007), Qui-quadrado, realizada pelo programa SPSS.

\section{DISCUSSÃO}

Durante a execução do projeto, a mortalidade dos camundongos foi alta, interferindo na amostragem baixa dos resultados das culturas em meio NNN e pesquisa de amastigotas pelo esfregaço. Em relação aos resultados das medidas das patas dos camundongos, das culturas e da pesquisa dos amastigotas, não houve diferença estatística entre os grupos NMG+azitromicina e NMG.

O resultado da diluição limitante mostrou grande diferença entre os grupos, (NMG: 528 leishmânias, e associação NMG+AZITR: 12.700 leishmânias), com diferença estatística significante, desfavorecendo o grupo NMG + azitromicina. Esse teste consiste na mais criteriosa avaliação do estudo. Houve diferença entre os resultados, sugerindo que a associação de drogas NMG+azitromicina teve ação bem menor sobre as leishmânias do que a droga NMG isolada.

Conclui-se que a associação das drogas não teve

Tabela 1: Resultados, antes e após tratamento, das medidas das patas dos camundongos C57BL/6 infectados $\operatorname{com} L$. (L.) amazonensis, nos grupos tratados com a associação N-metil-glucamina +azitromicina e $\mathrm{N}$-metil-glucamina isolado

\begin{tabular}{lcc}
\hline Grupos & Antes do tratamento $(\mathbf{m m})$ & Depois do tratamento a(mm) \\
\hline NMG & 39,30 & 31,75 \\
NMG + AZIT & 41,20 & 36 \\
\hline
\end{tabular}

teste T de Student p: 0,23

TABela 2: Resultados, após tratamento, das media do numero de promastigotas presentes nas culturas em diluição limitante realizadas com as patas trituradas dos camundongos C57BL/6 infectados com L.(L.) amazonensis, nos grupos tratados com a associação N-metil-glucamina +azitromicina e N-metil-glucamina isolado

Grupos Número de placas Elisa Média de amastigotas

\begin{tabular}{lll}
\hline $\mathrm{NMG}$ & 1 & 528 \\
$\mathrm{NMG}+$ AZIT & 1 & 12.700
\end{tabular}

NMG: N-metil glucamina AZIT: azitromicina 
maior eficácia do que o NMG no tratamento da LC experimental.

Os dados na literatura sobre a eficácia da azitromicina em LTA são controversos. Como vimos, estudos in vitro ${ }^{5,10}$ em camundongos ${ }^{5}$ e estudos clínicos ${ }^{7,12}$ demonstraram que a azitromicina pode ser eficaz para diversas espécies de Leishmania. Porém, estudo clínico realizado em Manaus com a azitromicina em 26 pacientes teve baixa taxa de cura e muitos efeitos colaterais. ${ }^{13}$ As diferenças entre a leishmaniose experimental e em humanos, bem como a variedade de espécies de Leishmania que causam a LTA, podem ser causa dessa disparidade de resultados.
Os reais mecanismos de ação tanto da NMG quanto da azitromicina sobre as leishmânias são desconhecidos, dificultando a hipótese de ação sinérgica entre essas drogas. Estes resultados levam a acreditar que não houve potencialização da $\mathrm{N}$-metil glucamina no tratamento da LC experimental quando a ela se associou a azitromicina. Seria desejável que esses resultados pudessem ser confirmados, assim como levado a termo o estudo do sinergismo de drogas no tratamento da LTA, já que a associação de drogas representa esperança diante da ameaça e do aumento da resistência terapêutica.

\section{AGRADECIMENTOS}

Agradecemos ao sr. Tércio Rodrigues Pereira, do Laboratório de Dermatomicologia, o apoio técnico, e à Fundação de Empreendimentos Científicos e Tecnológicos - Finatec o apoio financeiro parcial, bem como às dras. Jorgeth O. C. da Motta e Juliana S. F. e Silva.

\section{REFERÊNCIAS}

1. Sampaio RNR, Sampaio JHD, Marsden PD. Pentavalent antimonial treatment in mucosal leishmaniasis. Lancet. 1985;1:1097.

2. Netto PD, Marsden PD, Llanos-Cuentas EA, Costa JML, Cuba CC, Barreto AC, et al. Long Term follow-up of Patients with Leishmania (Viannia) braziliensis infection and treated with Glucantime?. Trans Royal Soc Trop Med Hyg. 1990;84:367-70.

3. Sampaio RNR, Marsden PD, Furtado T, Sampaio JHD. Avaliação do tratamento da leishmaniose cutâneomucosa com três esquemas diferentes de antimoniais pentavalentes. An Bras Dermatol. 1989;64:201-5.

4. Grogl M, Thomason TN, Franke ED. Drug resistance in leishmaniasis: its implication in systemic chemotherapy of cutaneous and mucocutaneous disease. Am Soc Trop Med Hyg. 1992; 47:117-26.

5. Krolewiecki A, Leon S, Scott P, Abraham D. Activity of azithromycin against Leishmania major in vitro and in vivo. Am J Trop Med Hyg. 2002; 67: 273-7.

6. Retsema J, Wenchi F. Macrolides: structures and microbial targets. Int J Antim Agents. 2001;18:S3-S10.

7. Prata A, Silva-Vergara ML, Rocha A, Krolewiecki SJC, De-Paula EV, Pimenta FG, et al. Eficácia da azitromicina no tratamento da leishmaniose cutânea. Rev Soc Bras Med Trop. 2003;36:65-9.

8. Tanyusel M, Bas AL, Araz E, Aybay C. Determination of intracellular efficacies of azithromycin against Leishmania major infection in human neutrophils in vitro. Cell Bioch Fun. 2003;21:93-6.
9. Michie C. Anti-inflammatory activity of macrolide antibiotics. Trends Mol Med. 2002;18:547.

10. Oliveira-Silva F, Pontes LA, Rabello A. In vitro activity of azithromycin against new world Leishmania species. Abstract Book of Third World Congress on Leishmaniosis. Palermo- Terrasini, Sicily, Italy: Editora of the Veterinary Institut of Palermo; 2005. p. 25.

11. Teixeira AC. Avaliação da eficácia da azitromicina no tratamento da leishmaniose cutânea em Manaus, Amazonas, Brasil [dissertação]. Faculdade de Medicina do Triângulo Mineiro Uberaba (MG): Faculdade de Medicina do Triângulo Mineiro; 2003.

12. Silva-Vergara ML, Silva LA, Maneira FR. Azithromycin in the treatment of mucosal leishmaniasis. Rev Inst Med Trop Sao Paulo. 2004; 46:175-7.

13. Lima HC, Bleyenberg JA, Titus RG. A simple method for quantifying leishmania in tissues of infected animals. Parasitol Today. 1997;13:80-2.

ENDEREÇO PARA CORRESPONDÊNCIA / MAILING ADDRESS:
Raimunda N. R. Sampaio
SHIS QI 25, conjunto O2, casa O1-Lago Sul
71660220 Brasília DF
Tel.Ifax: 5561336713316133673825
E-mail: rsampaio@unb.br

Como citar este artigo/How to cite this article: Sampaio RNR, Lucas IC, Costa Filho AV. O uso da associação azitromicina e N-metil glucamina no tratamento da leishmaniose cutânea causada por Leishmania (Leishmania) amazonensis em camundongos C57BL6. An Bras Dermatol. 2009;84(2):125-8. 